\title{
CONSTRUCCIÓN SOCIAL DE LOS HÁBITOS DE CONSUMO EN LAS PERSONAS MAYORES
}

\section{SOCIAL CONSTRUCTION OF CONSUMPTION PATTERNS IN THE ELDERLY}

\author{
AUTORES \\ Pedro Sánchez Vera: Profesor de sociología en la Universidad de Murcia (España) \\ psvera@um.es
}

\section{CURRÍCULUM VITAE}

Profesor de sociología en la Universidad de Murcia. Doctor en sociología y licenciado en filosofía por la especialidad de educación. Ha sido Director de investigación del Instituto de Ciencias de la Educación de la Universidad de Murcia. Fue Director de la Escuela Universitaria de Trabajo Social en la Universidad de Murcia y del Grupo de Investigación Sociológica del Bienestar Social y del Envejecimiento (E-055-04). Ha dirigido dos tesis doctorales y es autor de numerosos artículos científicos.

\section{RESUMEN}

Los hábitos de consumo es un asunto de indudable calado teórico, pero con una inusual dimensión práctica. Cómo se contraen, cómo influye la socialización del sujeto en sus distintas etapas vitales, económicas y familiares, la consistencia y el nivel de esos hábitos a lo largo de la vida del sujeto, la influencia de la sociedad de consumo en los mismos, etc. 


\section{PALABRAS CLAVE}

Consumo - Personas mayores - Sociedad

\section{ABSTRACT}

Consumption habits is a matter of undoubted theoretical importance, but with an unusual practical dimension. How to shrink, how it influences the socialization of the subject in its various stages of life, economic and family, consistency and level of those habits over the subject's life, the influence of the consumer society in the same, and so on.

\section{KEY WORDS}

Consumer - Elderly - Society

\section{ÍNDICE}

1. El tiempo y los hábitos de consumo

2. Los mayores y los hábitos de consumo

3. Efectos generacionales, del ciclo de vida familiar y de la situación económica

4. Percepción del dinero y de los bienes de consumo en el consumidor mayor

5. Microsociología de los hábitos de compra de los mayores

6. Bibliografía 


\section{El tiempo y los hábitos de consumo}

Los hábitos de consumo es un asunto de indudable calado teórico, pero con una inusual dimensión práctica. Cómo se contraen, cómo influye la socialización del sujeto en sus distintas etapas vitales, económicas y familiares, la consistencia y el nivel de esos hábitos a lo largo de la vida del sujeto, la influencia de la sociedad de consumo en los mismos, etc.

Los hábitos de consumo varían de un momento histórico a otro, pero existe una conexión en términos de "continuidad" y hasta cierto punto de servidumbre hacia los hábitos anteriores existentes y socialmente determinados. Pero al ser los hábitos de consumo producto del concurso de procesos sociales, culturales y personales, estos también varían a lo largo de la vida de un sujeto, ya que cambian las necesidades, y por supuesto, los gustos y preferencias del sujeto ante el consumo. Que por otra parte está generando nuevos órdenes de necesidades y de productos.

Si una categoría merece ser enfatizada respecto al consumo, ésta es el tiempo, pues no sólo se trata del tiempo histórico, sino de las secuelas y de los efectos de éste en las distintas generaciones, en la sociedad y en los individuos. El tiempo (tempus), en tanto que temporada está ligado a la caducidad en el sentido amplio de los productos en la sociedad de consumo; así como también a la estacionalidad de los consumos en distintas estaciones (climáticas) del año, o en función de distintos periodos de consumo nacidos o recreados en la sociedad de consumo (navidad, rebajas, promociones, efemérides diversas, etc). Que la sociedad de consumo fagocita e instrumentaliza los procesos sociales y culturales en términos de consumo, es un asunto en el que ya nos han puesto en antecedente y desde distintas perspectivas los grandes especialistas (v.g: Veblen, Bell, Friedman, Marx, From, Bourdieu, Baudrillard, etc). 
El paso del tiempo (y los sistemas de necesidades para cada momento social y personal) deja sus efectos sobre las distintas generaciones y sobre los individuos. La "generación" tiene dos dimensiones, la de "verticalidad" en tanto que sucesión de descendientes y la "horizontalidad" como coexistencia en un mismo momento de generaciones diferentes. Así, sabemos, que los hombres nacidos en distintos momentos viven y experimentan acontecimientos diferentes, y un mismo hecho o acontecimiento tiene efectos diferentes en función de la edad a la que se perciba, ya que existe un bagaje de experiencias cumulativo del que somos producto. De esta forma, y referido al consumo, un mismo producto o una generación de ellos, como por ejemplo, la telefonía móvil, va a tener un efecto distinto en una generación de persona mayores y otra mucho más joven. Eso no quiere decir que el consumidor mayor vaya a quedar al margen de esos fenómenos. Con independencia de que las teorías del cambio social inciden en la distinta posición de los sujetos en razón de la edad ante un mismo fenómeno, sin embargo estamos cansados de ver que junto a la edad (generación), existen también otras categorías que a veces pueden cobrar la misma entidad que la propia edad. No es menos cierto que la existencia de algunos rasgos comunes entre los mayores, tales como la situación económica que se deriva de ser en su mayoría pensionistas, están condicionando su posición respecto al consumo.

Pero en cualquier caso, nos faltan estudios comparativos con suficiente entidad analítica para poder deslindar y clarificar con nitidez, qué factores de los que afectan a las actitudes a las percepciones y al comportamiento de consumo, vienen determinados propiamente por la edad, y cuáles vienen determinados por otros factores (situación económica y patrimonial, familiar, laboral, educativa, género, etc).

A efectos de conocer mejor los surcos que ha dejado el tiempo en el consumidor mayor, o dicho de otra manera, los efectos generacionales respecto a la contracción de hábitos de consumo, sería deseable un mayor número de estudios comparativos 
entre sujetos mayores, pues resulta relativamente fácil y recurrente atisbar diferencias generacionales. Pero desde la perspectiva metodológica y a efectos de avanzar en el conocimiento del consumidor mayor, sería muy enriquecedor conocer el comportamiento de distintos subgrupos de mayores, con diferente condición económica, familiar, social, cultural, etc. De esta manera sabremos mejor el alcance del efecto generación -referido al consumo-, que por supuesto es muy importante, pero también sabremos si inciden (y de qué manera lo hacen) otras variables tales como las actitudes individuales, la trayectoria social de cada sujeto: movilidad social personal, biografía individual, y por supuesto otras tales como género, nivel de instrucción, situación familiar, estado de salud, etc.

Desde la perspectiva metodológica, para conocer la construcción de los hábitos de consumo en el consumidor mayor, serían deseables estudios que tomaran en consideración que un sujeto ha pasado a lo largo de su vida por distintos momentos de la sociedad de consumo y cada uno de ellos los percibe a una edad, existiendo una continuidad en la trabazón de experiencias acumuladas.

El esquema sería el siguiente:

A. Cronología de fenómenos de consumo vividos por un sujeto a lo largo de su vida.

B. Edad personal a la que ha experimentado los distintos fenómenos de consumo.

Fases de consumo vividas:

Momento I (edad A.1)

Momento II (edad B.2) (A.1+B.2)

Momento III (edad C.3) (A.1+B.2+C.3) 
Según el esquema anterior, cada sujeto vive cada momento de consumo a una edad determinada, siendo producto del total de momentos vividos y de la situación personal en la que vive cada momento.

El nivel de vida de un sujeto en la sociedad, es la resultante de poner en juego su poder adquisitivo y sus hábitos de consumo. Como hemos señalado, la sociedad de consumo (a través de los canales de persuasión) introduce nuevos hábitos de consumo (y de compra), pero resulta difícil establecer una separación clara entre la incidencia de las costumbres y la de los precios. El precio de los productos y lo que ello implica en la sociedad de consumo a través de ofertas, promociones, publicidad persuasiva, etc, también tiene sus efectos en los hábitos de consumo.

Sería interesante conocer con más detalle, qué grado de influencia tienen los precios en los hábitos de consumo de los mayores. De esta forma resultaría muy enriquecedor conocer también:

La incidencia de los precios en los hábitos de consumo entre sujetos mayores de distinto poder adquisitivo, a efectos de poder independizar los efectos de la edad (a través del conocimiento científico de fenómeno) y los de otras variables.

La trayectoria económica, familiar y de movilidad social de distintos subgrupos de mayores.

La incidencia de la movilidad social de un sujeto en sus hábitos de consumo. 
Las aportaciones del Pierre Bourdieu sobre los hábitos de consumo y sobre la sociología del gusto, son extraordinariamente enriquecedoras, pues ponen sobre el tapete la incidencia del origen social y de la movilidad social individual sobre los hábitos de consumo (Bourdieu P, 1.988).

A nivel general, y con independencia de los procesos de movilidad social (si es que esto fuera posible), referido al consumidor mayor, podemos hacer las siguientes apreciaciones:

-la situación económica de los mayores tiende a degradarse cuando se llega la condición de jubilado y/o de viudez.

-los mayores tienen cierta experiencia en adecuarse a una nueva situación económica ya que a lo largo de la vida han pasado por distintas fases.

-los mayores pueden introducir en mayor medida que otros colectivos cierta racionalidad y escepticismo al consumo, sin por ello dejar de ser un segmento creciente y rentable.

A través de las distintas fases de la vida, el sujeto ha ido cambiando sus hábitos de consumo, adaptando éstos a sus situación económica y familiar y a la evolución de sus gustos y preferencias (cuando se está en disposición de poder elegir). El consumo es, fundamentalmente, un fenómeno familiar, y es difícil conocer con detalle la estructura del gasto en las distintas fases del ciclo de la vida de un sujeto. Diferentes estudios han puesto de relieve cómo cada una de las etapas o ciclos de vida familiar del sujeto llevan emparejados una serie de gastos (Ruíz de Maya, 1.994). Con todo, existe una cierta orfandad de trabajos de investigación sobre el consumo familiar de los mayores en España. 
Ciertamente que muchos de los modelos teóricos, sobre comportamiento de los consumidores utilizados por el marketing, miran más los factores que impulsan a consumir un determinado producto y/o una marca concreta. Es por esto que algunos autores entiendan que ese tipo de literatura (referido al marketing) deba ser denominada como de "comportamiento de compra" y no como de "comportamiento del consumidor" (Navarro M, 1.987:500-501), pues los aspectos sociales del consumo son básicos y nunca deben ser reducidos a la parte psicológica. Las implicaciones y el estatuto teórico del consumo suponen toda una relación social tanto en la función como en la forma o "signo" del objeto de consumo (Pérez-Agote A, 1.978), y de otra parte, desde el punto de vista metodológico, la demanda de objetos de consumo está entreverada con modelos sociales generales (Ortí A, 1.994), que no le son ajenos al consumidor mayor. Con respecto al consumo de las personas mayores en España, éste no podrá ser aislado de las diferentes características que tienen modelos de consumo más globales y su evolución específica (Alonso, LE., Conde, F., 1.994; Conde, F., 1.994).

\section{Los mayores y los hábitos de consumo}

La situación social de la vejez se ve marcada por la confluencia de una serie de circunstancia que van a definirla. Diferentes teorías sociológicas sobre la misma, han puesto de relieve cómo hay un proceso de "desenganche" de los mayores del medio social (Cumming E, Henry W, 1.961). A esa situación contribuye la pérdida de roles que supone el abandono del trabajo y la pérdida de poder adquisitivo (Gubrium JF, 1.973). Siendo ciertas y centrales las limitaciones estructurales que suponen los factores sistémicos en la construcción social de la vejez. Sin embargo, y aún existiendo importantes bolsas de pobreza entre los mayores (Alfageme A, 1.999), la mejora en la situación económica de los mayores, tanto desde una perspectiva cronológica como con respecto a otros grupos sociales (Sánchez Vera P, 2.000), las nuevas actitudes de éstos a vivir la vejez de manera más activa y menos 
estigmatizada, han contribuido a mejorar sensiblemente la inserción social de los mayores en España.

Quizás lo más característico del caso español haya sido la tardía pero decidida irrupción de los mayores en el mundo del consumo. La relación sujeto-sistema que se establece a través del consumo merece una lectura de la sociología en la que integre las perspectivas de dos ámbitos disciplinares raramente puestos en conexión: la sociología de la vejez y la sociología del consumo.

La vinculación al consumo es un "signo" (Baudrillard) y un deseo de inserción social. en este sentido, el consumidor mayor merece ser tenido más en consideración con una perspectiva más holística -esto es, sociológica- que la que tiene la economía, que desde su práxico devenir, se ha dado cuenta de manera decidida (sobre todo los especialistas en investigación de mercados) de la importancia de este segmento de consumidores. Con independencia de las limitaciones y frustraciones que puede generar y genera la sociedad de consumo, sin embargo, en la medida que los mayores manifiesten actitudes más vitalistas y positivas hacia la cultura económica y el consumo, podremos hablar de una mayor inserción social y de una calidad de vida más autónoma e independiente.

Al analizar los hábitos de consumo de los mayores en España, hemos de partir del principio de que cada año están entrando generaciones nuevas a la edad de 65 años, y que cada vez, en más cantidad, han sido partícipes de la sociedad de consumo española, a modo de ejemplo, un sujeto que el año 2.000 haya cumplido los 65 años, tenía 30 a mitad de la década de los sesenta. Sin embargo, la sociedad de consumo en España entró algo más tarde que en la mayoría de países de nuestro entorno socioeconómico, tal como señalan distintos especialistas en la materia (v.g: Alonso LE, Conde F, 1.994; Conde F, 1994:147-148). De esta manera, los mayores actuales -con grandes diferencias según cohortes, género, tipo de hábitat, y niveles económicos y 
de instrucción-, ya conocieron algo tarde el fenómeno del consumo de masas, con lo que en general no son un colectivo imbuido plenamente de la mentalidad consumista, de ahí que un cierto corte generacional, deje a estos grupos etáneos alejados del consumo masivo e indiscriminado. Sin embargo, las generaciones nacidas a partir de mediados de los años cincuenta, ya han vivido y se han socializado desde sus primeros años de vida con la sociedad de consumo.

Una pregunta que debemos hacernos es si la categoría edad -referido al segmento de mayores de 65 años- representa, por sí misma, una categoría suficiente y con entidad propia, digna de ser tomada en consideración por los especialistas en comportamiento del consumidor. La respuesta a la cuestión anterior no es sencilla, a pesar de que exista un creciente interés por conocer las necesidades, las demandas y los anhelos de este consumidor.

Desde la perspectiva de los especialistas en introducir productos especializados que satisfagan las necesidades y demandas del consumidor mayor, así como desde la perspectiva de los especialistas en marketing e investigación de mercados; la respuesta no tiene duda: el segmento de consumidores mayores es numéricamente creciente, y económicamente rentable. Nadie duda que la rentabilidad económica proviene a su vez entre otros de los siguientes factores:

-el potencial cuantitativo del segmento.

-la mejora experimentada en la situación económica de los mayores

-la presencia de actitudes vitalistas que favorecen la integración social

Sin embargo, los problemas más habituales con que tienen que vérselas estos profesionales -referido al consumidor mayor-, están relacionados con la búsqueda de 
una adecuación entre fines (quién y qué) y métodos (mensajes y canales). En un mercado cada vez más segmentado y con mayores niveles de complejidad, el problema se plantea cuando la categoría "edad" se entrevera con otras tantas.

Ciertamente que la sociedad de consumo se presenta cada vez más segmentada por subsegmentos especializados de consumidores (sociedad de públicos en términos del profesor Castillo Castillo), y que atienden al juego de distintas categorías sociales y personales. Referido a la categoría edad, sin embargo, los productos que atienden necesidades de los mayores (por tanto más dirigidos a este tipo de consumidores), como aquellos otros productos que satisfacen necesidades y demandas sociales del conjunto de la sociedad, pero que pueden ensanchar su mercado entre sujetos mayores, deben ser extremadamente escrupulosos a la hora de dirigirse al consumidor mayor, y entreverar la edad con otras categorías sociales. En suma, se trata de vincular desde la lógica y desde la dinámica interna de la sociedad de consumo al sujeto mayor. Cuestión esta, que a la postre es compleja, y que desborda las pretensiones aproximativas de este trabajo. Pero en cualquier caso nadie duda que, desde la lógica interna del sistema, el consumo es un elemento de integración social de un colectivo "sistémicamente descolocado". Así, a la postre, tres, al menos, son los problemas básicos a sortear por el mercado frente al consumidor mayor:

1. Que el consumidor mayor desea sentirse integrado en otros segmentos distintos al de la edad (género, clase y status, grupos de referencia, etc).

2. Que la categoría edad adquiere carácter regresivo (transposición de imágenes negativas sobre la vejez), y que justamente, en el caso de los mayores, se trata de integrarla en otros grupos de menor edad. 
3. Que uno de los "leitmotiv" de la sociedad de consumo es el integrarnos en otras categorías sociales entre las cuales la juventud (antítesis de la vejez), se aproxima más al trinomio salud-belleza-vida.

4. Que entre los consumidores mayores habrá rasgos comunes que obedecen también al hecho de compartir aspectos comunes; pero también coexistirán tantas subcategorías -subsegmentos, si seguimos hablando de mercado- como tipologías hay en el resto de consumidores, aunque lógicamente algunas de ellas serán más preeminentes que otras entre los mayores.

Lo que los economistas llaman la elasticidad de la demanda no es más que la confluencia de factores sociales objetivos que inciden en el incremento de la demanda al sumarse distintos colectivos. En lo concerniente al consumidor mayor, se observan entre otros, los siguientes factores:

- El creciente número de productos específicos y dirigidos directamente a un consumidor mayor (salud, alimentación, cuidado e higiene, atención, ocio, etc).

- El creciente número de productos a los que por primera vez y de manera masiva tienen acceso o se incorporan los consumidores mayores (ocio, comunicación, etc).

- La mejora en la imagen social de los mayores y su creciente implicación social a través del consumo (sin negar con esto otros planteamientos más críticos sobre exclusión o "desenganche" social de los mayores). 
- La gran capacidad de la sociedad de consumo de innovar constantemente la oferta de productos, bien sea mejorando las ya existentes o introduciendo nuevos productos.

En una breve aproximación a la construcción de los hábitos de consumo, éstos tienen varias dimensiones. Cada una de ellas tiene su incidencia en la realidad objetiva de los hábitos que cada consumidor mayor va a tener:

- Efecto generación

- Biografía personal (movilidad social)

- Situación económica y patrimonial

- Situación y ciclo familiar (de su hogar y el de su allegados)

- Percepción subjetiva de la situación económica personal y general de la sociedad

- Actitudes subjetivas individuales ante el consumo

- Grado de decisión personal con el que se relaciona respecto al consumo

- Grado de autonomía física y mental o psicológica

Las actitudes económicas de los mayores ante fenómenos como el consumo, vienen determinadas por diferentes variables, siendo sin duda las más sobresalientes las referidas a su situación económica (tipologías), su situación familiar y su salud. Pero también intervienen variables de corte subjetivo que están referida a las propias actitudes vitales del mayor.

Si las situaciones económica y patrimonial son importantes en los hábitos de consumo, no menos importantes son las capacidades de decisión en el seno familiar. Existe una alta correlación entre el status económico de cada sujeto dentro de la unidad familiar y su posición dentro de la misma. Como es sabido, esta posición conlleva la interacción de sus hábitos con los de quienes les rodean en el ámbito 
familiar. Esa interacción puede acabar troquelando o incidiendo en los hábitos del resto de miembros de la unidad familiar.

El primer elemento a poner en juego referido al consumo, es el poder adquisitivo, aunque no sea el único factor a considerar, y menos en el caso de los mayores, donde estamos cansados de ver casos -que aunque sean excepcionales tienen altas dosis de simbolismo cultural- de mayores que viven en la mayor austeridad cuando no en la precariedad y que disponen de ingresos altos. En cualquier caso, es evidente que la jubilación, con la merma de ingresos mensuales que supone, impone una contracción en el consumo del mayor.

Como es bien sabido, el nivel de vida está articulado en torno a procesos individuales y familiares, que se estructuran en torno al poder adquisitivo y a los hábitos de consumo. El mayor, ciertamente tiene unos hábitos de consumo relativamente arraigados, que podrían operar negativamente en su estructura de consumo al llegar a una nueva situación (la jubilación) en la que se produce una merma de poder adquisitivo. Sin embargo, el mayor, cuenta en su haber, con que tiene cierta experiencia en la administración de su poder adquisitivo. Nadie como él, suele objetivar e interiorizar su situación en términos de consumo con tanta dedicación y eficacia (fuerza obliga). De una parte, ha pasado diferentes etapas de su vida en las que ha tenido que adecuar su consumo a las circunstancias individuales (ingresos) y familiares (ciclos de vida). De otra, sus grandes necesidades suelen estar cubiertas, aunque lógicamente surgen otras nuevas (v.g: asistencia sanitaria, servicios sociales), las cuales van a generar una demanda y gasto mayores del sistema público, lo cual está ligado a la mayor esperanza de vida (Moragas R, 1.991:197).

Con todo, la población de mayores (sobre todo en España), aún teniendo rasgos diferenciales, tiene elementos cultural-generacionales comunes que sesgan y definen su cultura económica y que, en consecuencia, van a determinar su posición respecto 
al consumo. Estos rasgos vienen muy marcados por la cultura económica de la subsistencia, al ahorro en el sentido más tradicional (privaciones), y a la contracción y al control del gasto en todos sus capítulos, aun por encima de su poder adquisitivo real.

No debemos olvidar un elemento subjetivo del consumo que es referido a los niveles y los hábitos de consumo adquiridos, que hacen que el mayor en principio, por el hecho de pasar a la situación de jubilado o a ser pensionista (por viudez, invalidez u otras circunstancias) tenga que adecuar sus hábitos de consumo a la nueva situación (económica o familiar). Es verdad que el hecho de tener unos hábitos adquiridos puede operar negativamente en la calidad de vida del anciano que debe moderar sus niveles de consumo y aquilatar el gasto hasta sus últimas consecuencias. Pero, como hemos señalado, también es verdad, que el mayor tiene cierta experiencia en regular su consumo adecuándolo a su propio ciclo familiar y de consumo, pues ha pasado a lo largo de su vida por diferentes vicisitudes económicas -producto o consecuenciadel juego de procesos objetivos y subjetivos. Lo que es evidente es que la edad, desde el punto de vista cronológico (y en tanto que suma acumulada y exponencial de experiencias), introduce factores objetivos, pero igualmente importante es el contenido o características de las situaciones vividas y que le han hecho seguir procesos de maduración determinados, que en el caso del consumo suelen ser la racionalidad económica, el ahorro y la contención del consumo.

El segmento de consumidores mayores, ya es una parte importante del mercado numéricamente hablando. Baste decir que en el año 1.996 (Padrón Municipal de Habitantes) representaban ya el 15,47 \% del total de la población española. Sin entrar en proyecciones demográficas, este peso relativo se va a ver incrementado progresivamente, estimándose que, en el año 2025, este segmento de personas mayores (se refiere a mayores de 65 años) estará en torno al 22 \% del total de la población española. Ni que decir tiene que la disminución de la natalidad española, 
la más baja del mundo con un índice sintético de natalidad (número de hijos por mujer) de 1,15 (INE: 1.999), y donde 15 de las 17 Comunidades Autónomas tienen un crecimiento negativo, es un factor a tener en cuenta al analizar el envejecimiento de la población española. Por la parte alta de la pirámide de población, la llegada a la edad de 65 años de las generaciones provenientes del "baby boom" (nacidos entre 1.959 y 1.969, y particularmente los nacidos en el segundo lustro de los años sesenta: entre 1.965 y 1.969), van a hacer crecer la población de mayores de 65 años extraordinariamente. Así entre el año 2.024 (nacidos en 1.959) y el año 2.034 (nacidos en 1.969) se va a producir el máximo de crecimiento de la población mayor de 65 años en España. Por otro lado, la esperanza de vida de los españoles se encuentra entre las más altas, situándose en una media de 84,4 años para las mujeres y de 78,2 para los varones (INE: 1.999).

Por otra parte, esas generaciones ya han vivido y se han socializado desde sus primeros años de vida con la sociedad de consumo, siendo generaciones de mayores que van a venir caracterizadas por poseer un mayor poder adquisitivo que las actuales.

Es cierto que la edad -y las experiencias generacionalmente vividas y acumuladas-, marcan al sujeto en sus actitudes ante la vida, pero que hay muy diferentes tipos de mayores con actitudes vitales igualmente distintas. Y en el asunto del consumo que aquí nos ocupa, dichas actitudes van a mediatizar la propia estructura de consumo que cada sujeto va a tener. El consumo puede aportar bienestar y, llevado con sensatez, puede alargar la vida y hacerla más placentera. Esas actitudes vitalistas para consigo mismos y en donde hay un proyecto de vida propio (por fortuna cada vez más presentes entre los mayores), en el que hacen y disfrutan de bienes y consumos a los que antes nunca pudieron tener acceso (bien por falta de dinero o por circunstancias familiares), no tiene por qué estar enfrentado -de hecho, así suele ocurrir- con el altruismo y la generosidad para con los suyos. 
Referido a las etapas en las que existen personas mayores dentro del hogar, las que siguen son las etapas del ciclo y los bienes y servicios de consumo más usuales en cada una de ellas: 1) En la fase de Nido lleno III (matrimonios maduros con hijos dependientes), los bienes más usualmente consumidos eran los siguientes: educación universitaria, segundo automóvil, mobiliario y hogar, libros y revistas, viajes. 2) En la fase de Nido vacío (matrimonios mayores sin hijos viviendo en casa): mejoras del hogar, viajes, planes de pensiones, productos de inversión, servicios médicos. 3) Sobreviviente (personas mayores que se han quedo solas): transporte, productos farmacéuticos, ocio y recreación, viajes, servicios domésticos.

A partir de los datos existentes en España (INE), la clasificación por grupos poblacionales más parecida a la establecida por el comportamiento del consumidor, nos dice que los hogares formados por personas de más edad que suele coincidir con las fases de "nido vacío II" (matrimonio sin hijos que convivan con ellos) "nido vacío III" (matrimonio con uno de los cónyuges jubilado), y supérstite solitario, gastan más que la media, en términos relativos en los grupos: G1 (alimentación, bebidas y tabaco), G2 (vestido y calzado), G3 (vivienda, calefacción y alumbrado), y G5 (servicios médicos y gastos sanitarios). Como ponen de relieve algunos especialistas, "sería deseable una mayor profundización en el consumo de los hogares en los que viven mayores, aunque esta tarea no siempre es fácil, pues en la ECPF, del INE, los datos son por hogares y no por sujetos" (Grande Esteban I, 1993:31-32).

En cualquier caso, si tomamos en consideración el gasto anual medio según la edad del sustentador principal para los distintos grupos de gasto, tal como podemos apreciar en la Tabla No 1 referida a la Encuesta de Presupuestos Familiares (INE, 1.990-91), nos encontramos con que los hogares cuyo sustentador principal es un mayor de 65 años, gastan su dinero en mayor proporción que otros hogares en alimentación. 
TABLA NO 1

Gasto anual medio por hogar (\%) según edad del sustentador principal. España, 1990-91

\begin{tabular}{|c|c|c|c|c|c|c|c|c|}
\hline $\begin{array}{l}\text { Grupos } \\
\text { de edad }\end{array}$ & Alimentos & Vestido & Vivienda & Hogar & Salud & Transporte & $\begin{array}{c}\text { Cultura/ } \\
\text { Ocio }\end{array}$ & Otros \\
\hline $0-29$ & 23,1 & 10,5 & 10,5 & 6,5 & 3,2 & 17,4 & 7,4 & 21,3 \\
\hline $30-44$ & 27,1 & 11,6 & 9,5 & 7,0 & 3,0 & 15,1 & 8,2 & 18,4 \\
\hline $45-64$ & 27,9 & 11,2 & 9,4 & 5,9 & 2,9 & 14,8 & 7,3 & 20,5 \\
\hline $65+$ & 34,6 & 10,7 & 13,6 & 6,9 & 3,5 & 8,9 & 4,3 & \\
\hline
\end{tabular}

Fuente: INE, Encuesta de presupuestos familiares, 1990-91. 17,4

Uno de los fenómenos conocidos es, a diferencia de otros grupos de población (jóvenes), la existencia de un ocio no monetarizado por parte de los mayores, y esto a pesar de tener bastante tiempo libre. Tareas tales como ir al hogar del pensionista, pasear, tertulias y, sobre todo, televisión, mucha televisión, ocupan el tiempo del mayor (CIS, 1.995). En cualquier caso, los mayores, constituyen microsegmentos especializados caracterizados por una demanda diferenciada (Grande Esteban I, 1.993:23). Uno de los sectores importantes es el mercado del ocio, particularmente si va unido a los viajes (y a la salud: balnearios, termalismo, etc). El éxito de los programas de vacaciones del INSERSO, ha roto el esquema de quienes pensaban que a los mayores no les gustaba moverse. Ha bastado el hecho de poner unos precios muy asequibles para que haya ido creciendo exponencialmente la demanda de plazas. Como ha puesto de relieve Anna Cabré (1.993:19), las generaciones que van a llegar a la jubilación van a ser cada vez más móviles, incluido el ocio, el turismo, y la búsqueda de una jubilación "soleada".

3. Efectos generacionales, del ciclo de vida familiar y de la situación económica 
Sería interesante conocer con más detalle cómo se produjo tal cambio en las generaciones que hoy tienen más de 65 años en España. A modo de ejemplo, y tal como señalábamos al principio, los mayores que han cumplido 65 años (por poner un edad indicativa) en el 2000, nacieron en 1.935 y pasaron las penalidades de la postguerra, llegando a los dieciocho años en el 1.953 en plena crisis de postguerra. Posteriormente se socializaron con un sociedad de consumo emergente, la de los años sesenta, en edad de matrimonio (en 1.963 tenían 28 años). Posteriormente, la bonanza de los años 80 les cogió entrando en la cincuentena de edad y en la década de los noventa les ha cogido con los 60 años cumplidos. Seguir el progreso de esa generación en sus diferentes etapas y edades no es tarea fácil, pero es posible que su conocimiento nos de pistas para entender mejor algunas actitudes de los mayores sobre el ahorro y el endeudamiento. Es posible que se trate de generaciones que a lo largo de su vida han estado fuertemente endeudadas, y que al llegar a la edad adulta quieran tener algunos ahorros que les infundan seguridad (de la que carecieron en otros momentos). Continuando con esto, es posible que ese endeudamiento que padecieron se viviera con una cierta esquizofrenia interna, pues por un lado desearían ahorrar siguiendo valores tradicionales, pero por otro la venta a plazos y los atractivos de los nuevos consumos les condujeron a endeudarse en ciertas compras inducidos por el contexto social de la nueva sociedad de consumo de un lado y por otro "por las culturas y valores tradicionales que tenían en el ahorro un interés clave" (Alonso LE, Conde F, o.c: 205), como pudo ser por ejemplo el automóvil -como luego veremos-. Referida a la escasa capacidad de ahorro de los españoles de los sesenta Alfonso Ortí decía: "(...) los individuos parecen sentirse inseguros, confusamente culpables, porque observan que su capacidad de ahorro disminuye. Y esta disminución del ahorro no sólo les afecta personalmente reduciendo sus sentimientos de seguridad, sino también socialmente, como una expresión de su estatus, de su imagen ante los otros, de su prestigio. El ahorro tiende así a transformarse curiosamente en la medida de todos los valores sociales: tanto ahorras tanto vales (Ortí A, 1.968) 
Como ya hemos dicho, es cierto que la edad -y las experiencias generacionalmente vividas y acumuladas-, marcan al sujeto en sus actitudes ante la vida, pero que hay muy diferentes tipos de mayores con actitudes vitales igualmente distintas. Y en el asunto del consumo que aquí nos ocupa, dichas actitudes van a mediatizar la propia estructura de consumo que cada sujeto va a tener. El consumo puede aportar bienestar y, llevado con sensatez, puede alargar la vida y hacerla más placentera. Esas actitudes vitalistas para consigo mismos y en donde hay un proyecto de vida propio (por fortuna cada vez más presentes entre los mayores), en el que hacen y disfrutan de bienes y consumos a los que antes nunca pudieron tener acceso (bien por falta de dinero o por circunstancias familiares), no tiene por que estar enfrentado -de hecho, así suele ocurrir- con el altruismo y la generosidad para con los suyos.

Ante todo, queremos hacer ver, que siendo verdad que hay rasgos comunes en las personas mayores ante el consumo, si algo sabemos desde la sociología, es que hay sujetos concretos con sus propios valores y circunstancias objetivas. Junto a la edad (los hay con diferentes edades) y la situación económica-patrimonial; el nivel de estudios, el estado de salud, el género, la situación familiar, y la biografía laboral de cada sujeto, constituyen otros tantos elementos a considerar a la hora de conocer al consumidor mayor. Así este segmento de consumidores, teniendo algunos rasgos comunes entre sí, sin embargo, también presenta diferencias y características diferenciadas entre subgrupos (o subsegmentos).

Una de las características que más pueden homogeneizar a los mayores es la disposición de tiempo para el consumo. Es por ello que gusta del trato personalizado y sosegado, no descartando el ir al punto de compra habitual como un lugar en el que comunicar con otras personas. Con respecto a los hábitos de compra, el mayor dispone de tiempo, y el hecho de comprar, no sólo es una posibilidad de interacción social (con el comerciante o con otras personas, conocidas o no, que se encuentran en 
el mismo punto de venta), sino que también puede ser un entretenimiento. Así, el hecho de comprar es una "obligación" que ocupa-llena su tiempo y satisface al mayor. De esta forma, el hecho de comprar los bienes de consumo no duradero, principalmente los productos alimenticios es una obligación que suele ocupar un tiempo importante del mayor. En general, el consumidor mayor adquiere pequeñas cantidades y suelen hacerlo a diario, o con gran frecuencia, mientras pueden, a diferencia de sus hijos que tienden a almacenar productos y a comprar mensual o quincenalmente. Sabemos igualmente, que los mayores prefieren comprar por la mañana, evitando así las aglomeraciones, gustándoles más los pequeños establecimientos donde suelen recibir un trato más personalizado. De igual manera, hay una cierta "fidelidad" en el consumidor mayor a un establecimiento determinado, que entre otros sectores de la población.

El mayor, no es uno de los grandes objetivos de consumo, partiéndose de la idea no siempre acertada de que dispone de escaso poder adquisitivo, pero va ganando poco a poco espacio y atención. En efecto, son mayoritarios los mayores con recursos escasos y que deben hacer un minucioso control del gasto para llegar a fin de mes, pero también es verdad que existen mayores que en términos reales poseen un poder adquisitivo igual o incluso más alto que el que disponen otros grupos más jóvenes, los cuales perciben unos ingresos sensiblemente superiores a los de los mayores. El hecho de tener una casa pagada y unos hábitos de consumo "controlados", es un capital adicional importante. Tampoco hay que desmerecer el hecho de que también algunos mayores cobran pensiones relativamente importantes, máxime teniendo en cuenta que, en un alto porcentaje, tienen su casa pagada. No es extraño tampoco el que a la propia pensión (y la del cónyuge) tengan complementos provenientes de ahorro o de otras rentas. Sabemos -y lo saben sobre todo los bancos-, del espíritu ahorrador de los mayores españoles. Espíritu ahorrador al que no es extraño el hecho de que tengan menos gastos fijos, hecho entreverado con el propio estilo de vida austero del mayor. 
Diferentes estudios han puesto de relieve cómo, a medida que avanzamos en el ciclo familiar, disminuye el grado de decisión conjunta en el seno familiar, esto es, que los matrimonios jóvenes toman sus decisiones más colectivamente, mientras que posteriormente la tendencia es a una mayor autonomía individual (Ruíz de Maya S, 1.994). No se conoce suficientemente el hecho de si, con la jubilación, vuelven a compartirse ciertos niveles de decisión en la administración del gasto y del patrimonio.

Un tema de gran interés en cuanto a los cambios de hábitos de consumo, es el hecho de la viudedad. Este hecho, que afecta en mayor proporción a mujeres que a varones, suele suponer un cambio en la situación económica y familiar, teniendo también sus repercusiones en cuanto a las decisiones que deben tomar.

También el cambio de situación personal y familiar que supone la mudanza de estado civil (generalmente por causa de la muerte del cónyuge, y en mayor medida afecta a la mujer, al ser la que queda viuda) tiene importantes repercusiones económicas, que le hacen disminuir su poder adquisitivo. Pero tampoco hay que perder de vista el hecho de que, para muchas mujeres, esa nueva situación también les supone el poder tener acceso a la gestión y a la administración de su patrimonio, situación que no siempre era posible. Puede darse la circunstancia, de que, tras la situación de viudedad, con frecuencia, la mujer mayor siente la sensación de poder y de libertad con respecto al dinero, al haber estado la decisión económica -sobre todo en las generaciones más maduras de viudas mayores- altamente masculinizada.

Un factor relevante es el grado de autonomía personal de la mayor viuda respecto a los hijos. Un factor que ha caracterizado la cultura femenina ha sido su endogamia hacia el circulo familiar. Sin embargo, referido a la autonomía de la mujer mayor viuda, poco a poco se va observando una mayor autonomía en el poder decisional de 
su patrimonio y de su dinero. Deben concurrir en esta circunstancia variables generacionales, pero también otras referidas al cambio social y a los efectos que la cultura económica ejerce en la sociedad toda.

El consumo es, fundamentalmente, un fenómeno familiar, y es difícil conocer con detalle la estructura del gasto en las distintas fases del ciclo de la vida de un sujeto. Diferentes estudios han puesto de relieve cómo cada una de las etapas o ciclos de vida familiar del sujeto llevan emparejados una serie de gastos (Ruíz de Maya, 1.994). Con todo, existe una cierta orfandad de trabajos de investigación sobre el consumo familiar de los mayores en España. El segmento de consumidores mayores (65 y más años), ya es una parte importante del mercado numéricamente hablando. Baste decir que en el año 1.996 (Padrón Municipal de Habitantes) representaban ya el 15,47 \% del total de la población española. Sin entrar en proyecciones demográficas, este peso relativo se va a ver incrementado progresivamente, estimándose que en el año 2025 este segmento de personas mayores, estará en torno al 22 \% del total de la población española. Ni que decir tiene que la disminución de la natalidad española, la más baja del mundo con un índice sintético de natalidad (número de hijos por mujer) de 1,15 (INE: 1.999), y donde 15 de las 17 Comunidades Autónomas tienen un crecimiento negativo, es un factor a tener en cuenta al analizar el envejecimiento de la población española. Por la parte alta de la pirámide de población, la llegada a la edad de 65 años de las generaciones provenientes del "baby boom" (nacidos entre 1.959 y 1.969, y particularmente los nacidos en el segundo lustro de los años sesenta: entre 1.965 y 1.969), van a hacer crecer la población de mayores de 65 años extraordinariamente. Así entre el año 2.024 (nacidos en 1.959) y el año 2.034 (nacidos en 1.969) se va a producir el máximo de crecimiento de la población mayor de 65 años en España. Por otro lado, la esperanza de vida de los españoles se encuentra entre las más altas, situándose en una media de 84,4 años para las mujeres y de 78,2 para los varones (INE: 1.999). 
Las formas de convivencia de los mayores, así como la tipología de los hogares y el ciclo en que estos se encuentran es un fenómeno de extraordinario interés para el consumo, tal como han puesto distintos especialistas (Ruíz de Maya, 1.998). Así, la presencia de algún miembro de 65 o más años en el hogar, es más elevada cuanto mayor es el tamaño del hogar (Díez Nicolás J, 1.997:153), así, un 21,9 \% de los hogares de 5 miembros, un 32,0 \% de los hogares de 6 miembros y un 36,1 \% de los hogares de más de 6 miembros tienen en su seno a algún mayor. Como señala Díez Nicolás (o.c.), en cualquier caso, está reduciéndose el tamaño medio de los hogares, tanto por el crecimiento de los hogares unipersonales, cómo por la permanencia de los mayores con su pareja en sus hogares, así como por la gran disminución de la natalidad habida en España a partir de década de los ochenta. Así, aunque estén disminuyendo los hogares de 5 y más miembros, sin embargo, la presencia de un mayor número de miembros en un hogar no implica más hijos, sino mayor número de otras personas, en muchos casos progenitores de la pareja (Díaz Nicolás, o.c: 153)

Tal como hemos señalado más arriba, el precio también incide en los hábitos de consumo. Este asunto merecería una atención especial en el caso del consumidor mayor, ya que es conocido por los especialistas en la materia (Grande Esteban; I, 1.993: 52), que uno de los elementos más valorados por el mayor a la hora de adquirir un producto, es el precio. Este hecho no está reñido con una cierta tendencia del consumidor mayor a la fidelidad a un producto (o.c:84), ya que los hábitos de consumo del mayor están más arraigados que los del consumidor más joven, mostrando el consumidor mayor, menos interés por probar nuevos productos (probablemente porque son menos propensos a la innovación y, por tanto, a asumir riesgos), siendo de esta manera más difícil la introducción de un nuevo producto en el consumidor mayor, aunque, claro está, existen diferencias importantes según poderes adquisitivos y niveles y modelos culturales. Entre los temas que más interesan al consumidor mayor están el precio y el conocimiento del producto. En cualquier caso hay que ser extremadamente cautelosos a la hora de asociar ciertos 
hábitos homogéneos al consumidor mayor, pues los hábitos están condicionado por el status del anciano, esto es, por factores tales como sus niveles de renta e instrucción, así cómo por su situación familiar. Como pone de relieve un experto en el consumidor mayor: "existe una relación directa entre el nivel de renta y el nivel cultural y la predisposición a aceptar nuevos productos y servicios" (Grande Esteban I, 1.994: 54).

En cualquier caso, el precio del producto es mucho más mirado por el consumidor mayor que por otros segmentos de edades. Con independencia del destino que vayan a dar al mismo, tener algunos ahorros es un elemento central para el mayor. Sabemos, a través de muy variados estudios, que, el tener dinero, para el mayor es un hecho cargado de simbolismo. Pues no sólo lo ha trabajado y sabe mejor que nadie de lo que cuesta ganarlo y aún más ahorrarlo (a base de privaciones), sino lo que es más importante, el dinero reporta seguridad al mayor, pues entre otras cosas, la eventualidad de caer enfermo y de necesitar a alguien que lo cuide y atienda, necesita tener autonomía financiera. No olvidemos que el sentimiento de tener seguridad es la principal preocupación del mayor. Las carencias y penurias a las que han estado sometidos los mayores en España, les hace buenos administradores de sus economías domésticas, lo cual -no nos engañemos- es un valor capital de la cultura económica: el mirar la peseta.

Lo que parece evidente, en cualquier caso, es el hecho de que el mayor tiene que aquilatar su gasto al extremo, pues ha de administrar con rigor su magra pensión. De otra parte, dispone de tiempo sobrado para dotar de la máxima racionalidad económica a su conducta de consumo. Y por último, y a pesar de lo exiguo de las pensiones españolas y del pesimismo económico que determina el comportamiento del mayor, la toma de referencia con periodos anteriores de su propia situación económica en tanto que pensionista (no olvidemos la favorable evolución de las pensiones en España en los últimos 10 años) y aún más la toma de referencia con 
respecto a generaciones predecesoras en la jubilación que pasaron todas las penurias, es un hecho relevante.

Sin embargo, y de manera paradójica, el mayor, tiene que asumir y asume "lo económico" como uno de los contenidos y de los significados más afianzados en su cotidianeidad. De una parte, los temas de conversación frecuentes entre los mayores están referidos al dinero y a la administración de su economía doméstica, sin embargo están expropiados de ciertos conocimientos instrumentales imprescindibles. El bajo nivel de instrucción de los mayores los hace frecuentemente desconfiados hacia las mudanzas que la vida económica moderna impone.

También hay que observar que la mejora en la "cultura económica" de los españoles ha afectado extraordinariamente a los mayores. La cultura del ahorro es uno de los ejes centrales de cultura económica del anciano. Ya lo hemos dicho, el mayor, a pesar de su parca pensión, tiende a gastar lo imprescindible y aún menos, el resto lo ahorra o lo reparte entre sus familiares más allegados con los cuales convive o no, ya hemos hablado del papel de la pensión de los abuelos en el mantenimiento de muchos hogares españoles. Este factor en el que hay que insistir, sin que por ello tengamos que restar vitalidad al papel asistencial de la familia en España. En palabras de un experto "los dineros de los abuelos, en general, son dineros bien administrados por una generación sobria, parca, que ahorra en sus libretas, para luego financiar juguetes a los nietos pequeños, entradas a la compra del piso para los nietos y que tapan los agujeros de fin de mes de sus hijos" (...) "Es una generación que consume poco, y productos españoles, apagan la luz al salir, guardan las bolsas de plástico y las cuerdas y cintas de la tarta de cumpleaños. La gran función de las pensiones de la SS es la redistribución económica y social. (...) los abuelos y abuelas españolas, con su consumo ordenado, son una demanda que genera desarrollo y, sobre todo estabilidad económica. Son además un pacificador social, una memoria oral histórica 
(en el seno de la familia) que nos recuerda permanentemente de donde venimos" (un país pobre). (Gaviria M 1996:98).

Un buen número de depósitos de ahorro a plazo proveniente de mayores, se ha convertido en fondos de inversión. La disponibilidad de tiempo y el intercambio de opiniones entre los mayores en uno de sus temas preferidos hace previsible un crecimiento de esta cultura económica. Pero, en cualquier caso, y referido al ahorro, todo hace indicar que no es un cliente emprendedor y mucho menos aventurero. Referido al ahorro de los mayores, señala Moragas (Moragas R, 1.991:196-197) lo siguiente: "El Estado reconoce la importancia de las decisiones presentes de los futuros jubilados y trata de fomentar el ahorro con lo que aumenta el capital disponible para inversión, detrae dinero del consumo y controla la inflación (...), aunque (...) el propio ahorro se ve afectado por la inflación que devalúa en pocos años las pesetas ahorradas (...) debido a ello, la población puede preferir el consumo presente al ahorro y futura renta empobrecida, olvidando la previsión del futuro en aras del bienestar actual".

Ciertos elementos relacionados con la cultura del ahorro, como son las actitudes del mayor hacia la "reutilización" (sobre todo), la "recuperación" y el "reciclaje" de ciertos productos de su vida cotidiana, son de alguna forma elementos centrales de una cultura económica contraria al consumismo y al despilfarro, que a su vez forman parte del paradigma ecológico. Un reciente estudio realizado por la Comunidad de Madrid, ha puesto de relieve una manifiesta colaboración de las personas mayores en las tareas de discriminación de papeles y vidrios. Con independencia de las anteriores conductas típicamente cívicas y ecológicas, también el mayor, se familiariza con ciertas actividades de reparación y bricolage, muchas de las cuales están ligadas a la estrechez económica con que tiene o debe, o simplemente desea conducirse, y que le lleva por ejemplo a no llamar a operarios para pequeñas reparaciones domésticas. La disposición de tiempo libre, le permite igualmente 
realizar de grado estas tareas domésticas y pequeñas reparaciones. Estas conductas, son tanto masculinas como femeninas, aunque suelen ser más masculinas. La mujer, al quedar viuda también tiene que realizar frecuentemente actividades domésticas a las que no estaba habituada, y puede mostrar un comportamiento más dependiente que el varón en la realización de las mismas.

Pero, desde el punto de vista económico, hay un factor que en modo alguno debe pasar desapercibido: el papel de las pensiones en las economías domésticas. Como ponen de relieve diferentes investigadores (Pérez Ortíz L, 1.998) (Bazo MT, 1.996), las pensiones de los mayores en España tienen una importante función económica complementaria para las familias. En algo más de un tercio de los hogares españoles entra una pensión de la Seguridad Social (casi 8 billones de pesetas al año, que desde los bancos y sobre todo desde las cajas circulan animando la economía española).

\section{Percepción del dinero y de los bienes de consumo en el consumidor mayor}

El factor psicológico del valor del dinero y de los bienes materiales, adquiere connotaciones especiales cuando hablamos del sujeto mayor. De una parte los factores sistémicos que "desenganchan" al mayor de la sociedad y, por consiguiente, del valor objetivo de las cosas materiales, y muy particularmente del dinero, y de otra, la pérdida de referencias socialmente retroalimentadas sobre el verdadero valor de los bienes y de los productos en el contexto de la sociedad de consumo. La escisión que se produce entre valor de uso-función y valor simbólico del producto adquiere caracteres de radicalidad en el sujeto mayor, en donde la función (y su contextualización temporal, cuando lo adquirió o cuando le fue regalado) se sobrepone al "signo" o valor simbólico que se explica por sí mismo en el análisis de la sociedad de consumo. 
Es frecuente encontrar entre los sujetos mayores en su relación con el consumo una extraña relación con el dinero en tanto que valor de intercambio. Una cierta patología de pérdida de referencia sobre el valor real del dinero se une a la senilidad cuando el sujeto mayor queda anclado en el tiempo en el precio de los productos de consumo o cuando no aquilata adecuadamente la correspondencia entre precio-producto. Es esto así cuando el sujeto mayor atribuye un valor subjetivo al dinero acostumbrado a manejar precios muy inferiores y en donde el valor del dinero se correspondía a otro contexto económico y social. Esa pérdida de referencia en el valor del dinero, en efecto, es producto la mar de veces de la senilidad psicológica, pero también en la misma intervienen otros factores societarios que no siempre hacen tan nítida la frontera entre la "actitud senil" y la pérdida de referentes objetivos que se produce en muchos sujetos mayores al desvincularse relativamente de los procesos socioeconómicos vinculados al dinero.

En cuanto a los bienes materiales, la sociedad de consumo introduce permanente nuevos productos que no siempre despiertan el interés o llegan a seducir al consumidor mayor (a pesar de escuchar y visionar bastante publicidad). El valor simbólico que atribuimos a los bienes que nos rodean deben ser contextualizados temporalmente para ser justamente entendidos y comprendidos. Esa visión cronológica del valor de las cosas es básica para entender al consumidor mayor. El producto se valora social y personalmente en el contexto temporal donde es adquirido o poseído por el sujeto, y en donde ese producto tenía un valor objetivo. Una carga subjetiva es igualmente inevitable en el análisis de la subjetividad con la que se dirigen muchos consumidores mayores llegando al extremo de que, teniendo dinero suficiente, se muestran reacios a realizar cambios en instalaciones o en mobiliario doméstico con signos claros de deterioro y/o de disfuncionalidad, o sencillamente porque han aparecido nuevos productos que mejorarían la confortabilidad del sujeto mayor. 
Tampoco debe ser olvidada la carga afectiva de los objetos de los objetos para el sujeto mayor, muchos de los cuales forman parte de su historia personal y familiar (de su familia y la de sus propios antepasados). Ese valor afectivo es un valor de difícil estimación (como muy bien saben los peritos especializados en estas cuestiones), pero que en cualquier caso llena de contenido emocional a muchos de los bienes y objetos que rodean al mayor. Dentro de ese valor emocional, un factor colindante de ese valor subjetivo del objeto de consumo, lo tiene el contexto cultural en el que aquél objeto fue adquirido o poseído, así como con el esfuerzo con que se consiguió. Los objetos son una parte importante de la vida cotidiana de los sujetos de todas las edades y forman parte de la identidad (social, cultural, familiar) de los mismos. De esta manera un objeto sencillo sin valor objetivo, al estar cargado de emotividad (recuerdos, afectos, etc) adquiere valor subjetivo que hace difícil entender algunas posiciones el sujeto mayor en su relación con el consumo. Es en el contexto anterior en el que surgen ciertas conductas, comportamientos y hábitos del sujeto mayor que pueden estar a un paso de lo patológico en tanto que guardan y almacenan objetos de escaso o nula funcionalidad y/o valor real.

\section{Microsociología de los hábitos de compra de los mayores}

Para describir los rasgos más significativos en relación al consumo de los mayores, y de otras variables relacionadas con el mismo, nos basamos en los datos que el Centro de Investigaciones sobre la Realidad Social (CIRES), lleva poniendo a nuestra disposición periódicamente desde 1990. Las tablas que se han elaborado en el presente trabajo han sido llevadas a cabo a partir de los ficheros de datos proporcionados por el CIRES.

Los datos que arrojan estos estudios, son de gran utilidad, al desagregar los resultados por grupos de edad, así nos permite conocer el comportamiento específico de las personas mayores de 65 y contrastar, a su vez, si éste difiere de los demás 
grupos de edades. Otra de las ventajas que nos aporta este tipo de estudios, además de su accesibilidad, es poder realizar un cierto análisis longitudinal, ya que muchos de los "items" que nos interesan para nuestro análisis han sido incluidos en varias de las investigaciones realizadas en los sucesivos años, de este modo permite estudiar las posibles tendencias habidas en el comportamiento.

Partimos por lo tanto de la afirmación de que la edad es una variable que puede explicar comportamientos diferentes en los consumidores. Los mayores tienen unos hábitos de consumo bastante arraigados, son compradores expertos que han ido adquiriendo a lo largo de su vida innumerables bienes y servicios, muchos han sufrido privaciones importantes debido a las circunstancias políticas del país y llegaron un poco tarde a para ser socializados en la sociedad de consumo de masas.

TABLA No 2.

Porcentaje de los encuestados que se muestra de acuerdo con los ítems correspondientes.

\begin{tabular}{|c|c|c|c|c|c|c|c|c|}
\hline \multicolumn{2}{|c|}{$\begin{array}{l}\text { Total } \\
\text { Enc. }\end{array}$} & \multirow{2}{*}{$\begin{array}{c}\begin{array}{c}\text { Idea } \\
\text { clara } \\
\text { alir a } \\
\text { compr } \\
\text { ar }\end{array} \\
74 \\
\end{array}$} & \multirow{2}{*}{\begin{tabular}{|c} 
Comprancu \\
ando no les \\
quedamás \\
remedio
\end{tabular}} & \multirow{2}{*}{\begin{tabular}{|c|}
$\begin{array}{c}\text { Prefierenp } \\
\text { ago en } \\
\text { efectivo }\end{array}$ \\
87 \\
\end{tabular}} & \multirow{2}{*}{\begin{tabular}{|c}
$\begin{array}{c}\text { Fieles } \\
\text { amismoscome } \\
\text { rcios }\end{array}$ \\
65
\end{tabular}} & \multirow{2}{*}{\begin{tabular}{|c} 
Prefierencomprarc \\
ontado
\end{tabular}} & \multirow{2}{*}{\begin{tabular}{|c|}
$\begin{array}{c}\text { Miranl } \\
0 \\
\text { primer } \\
\text { oel } \\
\text { precio }\end{array}$ \\
\\
67
\end{tabular}} & \multirow{2}{*}{$\begin{array}{c}\begin{array}{c}\text { Lo más } \\
\text { importa } \\
\text { nte la } \\
\text { calidad }\end{array} \\
81\end{array}$} \\
\hline $\begin{array}{c}\text { Tot } \\
\text { al } \\
\text { Jul. } \\
91\end{array}$ & \begin{tabular}{|l}
1.2 \\
00
\end{tabular} & & & & & & & \\
\hline $\begin{array}{c}65 \\
y \\
\text { má } \\
\text { s }\end{array}$ & 196 & 75 & 64 & 89 & 70 & 91 & 57 & 75 \\
\hline $\begin{array}{c}\text { Tot } \\
\text { al } \\
\text { Oct } \\
.93\end{array}$ & $\begin{array}{l}1.2 \\
00\end{array}$ & 72 & 53 & 87 & 68 & 92 & 70 & 82 \\
\hline $\begin{array}{c}65 \\
\text { y } \\
\text { má } \\
\text { s }\end{array}$ & 196 & 70 & 60 & 93 & 70 & 93 & 65 & 76 \\
\hline
\end{tabular}

Fuente: CIRES, 1991 y 1993 


\begin{tabular}{|c|c|c|c|c|c|c|}
\hline Porcentaj & los & $\begin{array}{l}\text { TABLA } \\
\text { uestados q } \\
\text { tems corres }\end{array}$ & $\begin{array}{l}\text { A No } 3 \text {. } \\
\text { ue se mues } \\
\text { spondiente }\end{array}$ & $\begin{array}{l}\text { tra de acu } \\
\text { s. }\end{array}$ & rdo co & n los \\
\hline Tota & & $\begin{array}{c}\text { Compran cuando } \\
\text { pueden } \\
\text { productos }\end{array}$ & $\begin{array}{c}\text { No se fijan en las } \\
\text { marcas }\end{array}$ & $\begin{array}{l}\text { No les gusta } \\
\text { gastar dinero de }\end{array}$ & $\begin{array}{c}\text { No les } \\
\text { afecta la } \\
\text { publicidad }\end{array}$ & \begin{tabular}{|c|} 
Dudan \\
lo que \\
quieren \\
y tardan
\end{tabular} \\
\hline Total Jul. 91 & 1.200 & 72 & 59 & 52 & 70 & 51 \\
\hline 65 y más & 196 & 65 & 62 & 65 & 71 & 49 \\
\hline Total Oct. 93 & 1.200 & 74 & 59 & 57 & 70 & 56 \\
\hline 65 y más & 196 & 73 & 57 & 68 & 65 & 59 \\
\hline
\end{tabular}

De las Tablas 2 y 3, se puede afirmar que el grupo de las personas mayores, no constituye un segmento demasiado diferenciado del resto de la población, en cuanto a su comportamiento de compra, si bien existen una serie de diferencias que conviene resaltar. Son personas que tienen menos deseos de comprar, hay un mayor porcentaje de ellas que compra cuando ya no les queda más remedio (en el año 1.991 el 65\% y en el año 1.993 el 60\%, frente el resto de la población que presenta unos porcentajes de $56 \%$ y $53 \%$ en los respectivos años). Se puede decir que este menor impulso a la hora de comprar puede estar influenciado por dos variables, una de carácter biológico, debido a la menor autonomía que tiene este grupo de edad, ya que a veces precisan de compañía para ir de compras, y otra de carácter más generacional, ya que el hecho de haber atravesado momentos difíciles les ha hecho ser más cautos con el gasto y mantener un comportamiento más racional.

Si analizamos la forma de pago se trata de personas que prefieren pagar en efectivo en el año 1.993 el 93\% frente al 87\% de total de la población, y también muestran una mayor preferencia por las compras al contado frente la compra a plazos. Los consumidores maduros se muestran más reacios al uso de tarjetas de crédito, en parte esto es debido a que la adquisición de los hábitos de consumo tuvo lugar en una época en la que no existían estas, además subyace la idea de que el pago mediante tarjetas favorece el descontrol del presupuesto familiar. En la actualidad, la 
mayoría no valora la posibilidad de poder pagar con otros medios distintos del dinero, salvo quizá cheques y talones. El pago al contado lo consideran como un símbolo de status social, a parte de no haber sido socializados en la cultura económica del pago a plazos que empezó a utilizarse en nuestro país a principios de los años 60, con el origen de la sociedad de consumo.

También demuestran una mayor fidelidad que el resto de la población en lo que respecta al punto de venta elegido para realizar sus compras. Los mayores prefieren realizar sus compras en los mismos sitios de siempre donde ya les conocen y mantienen una relación de confianza con los vendedores, dejándose asesorar en algunos casos. Estos sitios elegidos suelen estar cercanos a su domicilio, ya que valoran bastante el factor de proximidad debido a las dificultades de desplazamiento que aumentan con la edad, y donde es posible que se encuentren a vecinos del barrio con los que puedan charlar, teniendo un carácter más lúdico la compra en los mayores que en los jóvenes.

En general, los consumidores mayores prefieren los establecimientos pequeños, próximos a su domicilio, donde reciben un trato personalizado. La fuerza de las ventas constituye un grupo socializador para los mayores, ya que por su edad y situación familiar, suelen sufrir problemas de soledad.

Los mayores se fijan menos en el precio que el resto de la población, en el año 1.991 la diferencia era de diez puntos, viéndose ésta rebajada a 5 puntos en el 1.993. Cuando se trata de llegar a segmentos de edad avanzada se parte de la premisa de que los precios deben de ser más bajos, ya que las menores rentas que perciben les confieren una menor capacidad de gasto, esto es discutible ya que la tercera edad tiene menos gastos fijos que el resto de la población (casa en propiedad, hijos independientes). La tercera edad dispone cada vez más de mayores ingresos que en otros tiempos, gozando así de un mayor poder adquisitivo. Los planes de ahorro y los de pensiones 
permitirán en el futuro un gran poder de compra a los mayores. Los jóvenes, más que los mayores le dan más importancia al precio, ya que asocian éste con calidades más elevadas. Los grupos de más edad valoran en los bienes y servicios otros atributos que pueden ser más importantes que los precios, tales como la calidad, la seguridad o la funcionalidad. Los consumidores mayores no suelen cambiar una marca ya conocida por otra que tenga un precio más bajo, porque quizá es mayor el riesgo que perciben ante la novedad de un producto.

En lo que hace referencia a los distintos tipos de riesgo; financiero, psicológico, físico y funcional son percibidos por los consumidores mayores con una mayor intensidad que el resto de la población. Esta percepción constituye un freno a la adopción de nuevos productos y servicios, siendo por ello muchos más lentos. No obstante, se ha comprobado que cuando mayor sea la renta y la cultura de las personas mayores, su autoconfianza e intensidad de las relaciones sociales, menor será la percepción del riesgo y mayor su semejanza con los grupos de población más jóvenes.

Los mayores son personas que adquieren en menor medida productos rebajados o en oferta, aunque los porcentajes parecen igualarse en la última investigación de 1993, el $74 \%$ del total de la población frente al 73\% de personas de 65 o más años. Este comportamiento se debe por una parte, a que los mayores evitan comprar en épocas de grandes aglomeraciones como puedan ser las rebajas, y también por la mayor fidelidad mencionada que puedan tener a los productos que han comprado toda la vida, no les atraen demasiado los productos que puedan estar en oferta, al presentarse para ellos como una novedad o cambio, para el cual se muestran más reacios.

Como se puede apreciar en las Tablas 2 y 3, los consumidores mayores son un segmento de la población que se muestra más reacio a gastar dinero que el resto, en el estudio de 1993 el 68\% de los mayores afirma que no les gusta gastar dinero, 
mientras que el resto de la población muestra un porcentaje más reducido, el 57\%. Los mayores, como hemos comentado con anterioridad, se encuentran menos imbuidos en los patrones típicos de la sociedad de consumo de masas, esto les hacer ser más precavidos a la hora de gastar su dinero, a lo que se une una mayor valoración que le puedan dotar a éste por haber vivido épocas de escasez.

A continuación, y a través de las Tablas 4 a 10, vamos a hacer un breve análisis basado en los estudios de CIRES-, a efectos de contrastar si los mayores presentan un comportamiento distinto al de otros grupo etáneos en la elección del tipo de establecimiento, bien sea éste: tienda, mercado, supermercado, gran almacén, hipermercados u otros tipo. También se analiza la relación entre el tipo de comercio elegido en relación al tipo de producto de consumo: alimentos frescos- ultramarinos, ropa y/o calzado, productos para el hogar o menaje, y electrodomésticos. El estudio es de octubre de 1993, y se pregunta por alimentos frescos y por ultramarinos, en lugar que por alimentos "a secas"; y por menaje, en lugar de productos para el hogar.

\section{TABLA No 4.}

Porcentaje de los encuestados que compran los Alimentos (Jul.91-Oct.91) Alimentos frescos - Ultramarinos (Oct.93) en cada tipo de establecimiento.

\begin{tabular}{|c|c|c|c|c|c|c|c|}
\hline \multicolumn{8}{|c|}{ Alimentos } \\
\hline & Enc. & Tienda & Mercado & SP & GA & $\mathbf{H P}$ & tros \\
\hline $\begin{array}{c}\text { Total } \\
\text { Jul.91 }\end{array}$ & 1200 & 24 & 14 & 41 & 2 & 7 & $*$ \\
\hline 65 y más & 196 & 30 & 16 & 34 & 2 & 2 & 1 \\
\hline Total Oct.91 & 1200 & 22 & 13 & 47 & 3 & 9 & $*$ \\
\hline 65 y más & 196 & 34 & 16 & 39 & 2 & 3 & 1 \\
\hline Total Oct.93 & 1200 & 31 & 24 & 27 & 3 & 6 & 1 \\
\hline 65 y más & 196 & 39 & 26 & 21 & 1 & 3 & - \\
\hline \multicolumn{8}{|c|}{ Ultramarinos } \\
\hline Total Oct.93 & 1200 & 22 & 10 & 39 & 5 & 13 & $*$ \\
\hline 65 y más & 196 & 36 & 10 & 34 & 1 & 7 & $*$ \\
\hline
\end{tabular}

Como se aprecia en la Tabla $\mathrm{N}^{0}$ 4, si bien todos los grupos de población eligen mayoritariamente para realizar sus compras de alimentos las tiendas y los 
supermercados, los consumidores mayores de 65 años, eligen para realizar las compras de este tipo de productos, en mayor medida, las tiendas de barrio que los supermercados. En Octubre de 1993, el 39\% de los consumidores mayores eligen las tiendas, frente aun porcentaje inferior (21\%) que elige los supermercados, tendencia que se ha visto incrementada con el tiempo. La proximidad al domicilio, el trato más personal con el comerciante, la fidelidad a la tienda "de toda la vida", la incomodidad de los pasillos de los supermercados, son algunas de las razones que hacen a los mayores preferir este tipo de establecimiento, frente al resto de la población que compra en mayor medida en los supermercados.

Otro aspecto a destacar es el mayor porcentaje de mayores consumidores que realizan la compra de alimentos en los mercados $\mathrm{y}$, sin embargo, el escaso número de consumidores mayores que visitan los hipermercados para realizar este tipo de compras (en Octubre del 93 el 3\%, frente al 6\% del resto de la población). La lejanía de su domicilio, la amplitud de los hipermercados donde a veces se sienten perdidos, la dificultad de desplazamiento, el hecho de no poseer carnet de conducir y depender de otras personas para acudir, hace que los mayores sean poco usuarios de este tipo de establecimientos.

Por lo que se refiere a los ultramarinos, pregunta desagregada en el cuestionario de Octubre de 1993, se introduce una diferencia significativa para el grupo de los mayores, éstos eligen para su compra en mayor medida las tiendas frente a los supermercados, mientras que en el resto de la población prefieren comprar estos productos en los supermercados (el 39\%, elige los supermercados y el 22\% la tienda). En relación a las grandes superficies también acuden en menor medida el grupo de 65 y más años (7\%), mientras que el resto de la población tiene un porcentaje del 13\%. Este comportamiento se repite en el caso de los grandes almacenes, donde los mayores sólo acuden en un 1\%, mientras que el resto de la población representa un $5 \%$. 


\begin{tabular}{|c|c|c|c|c|c|c|c|c|c|}
\hline Porcentaj & e los en & cuestados & $\begin{array}{l}\text { TABLA } \\
\text { que com } \\
\text { le estable }\end{array}$ & $\begin{array}{l}\text { No } 5 . \\
\text { an la Rop } \\
\text { imiento. }\end{array}$ & a y/ & /o e & Calzado & en cada & tipo \\
\hline & & & Ropa y/c & calzado & & & & & \\
\hline & $\begin{array}{c}\text { Enc. } \\
\text { normal }\end{array}$ & $\begin{array}{c}\text { Tienda } \\
\text { prestigio }\end{array}$ & Mercado & SP & GA & $\mathrm{HP}$ & Boutique & Boutique & Otros \\
\hline $\begin{array}{c}\text { Total } \\
\text { Jul.91 }\end{array}$ & 1200 & 52 & 4 & 4 & 23 & 4 & No preg. & No preg. & 8 \\
\hline 65 y más & 196 & 56 & 4 & 4 & 10 & 3 & & & 6 \\
\hline $\begin{array}{c}\text { Total } \\
\text { Oct.91 }\end{array}$ & 1200 & 35 & No preg. & No preg. & 33 & No & 22 & 2 & 5 \\
\hline 65 y más & 196 & 47 & & & 24 & & 11 & 1 & 10 \\
\hline $\begin{array}{c}\text { Total } \\
\text { Oct.93 }\end{array}$ & 1200 & 51 & 4 & 4 & 25 & 5 & No preg. & No preg. & 7 \\
\hline 65 y más & 196 & 52 & 7 & 4 & 20 & 2 & & & 6 \\
\hline
\end{tabular}

Fuente: CIRES, 1993.

Como se puede interpretar del análisis de la Tabla $\mathrm{N}^{0}$, para la compra de ropa y calzado, la mayoría de la población elige la tienda, pero en mayor medida son los mayores de sesenta y cinco años los que eligen este tipo de establecimiento. Por el contrario, los grandes almacenes son más utilizados por el resto de la población en Julio de 1991, el 23\%, mientras que los consumidores mayores sólo un 10\% realiza sus compras de calzado y ropa en estos establecimientos. El trato personal a la hora de comprar este tipo de productos hace que los mayores acudan en mayor medida a las tiendas especializadas cercanas a su domicilio, donde quizá los conozcan de toda la vida.

En lo que respecta a los consumidores mayores cada vez son más asiduos a realizar las compras de estos productos en los grandes almacenes, en Julio de 1.991 el porcentaje es de un 10\%, como hemos dicho antes, y en octubre de 1.993 de un $20 \%$.

En el cuestionario de Octubre de 1.991 se incluye las opciones de las boutiques, donde el porcentaje de mayores que acude a ellas es la mitad que el colectivo global de la población. 


\section{TABLA No 6.}

Porcentaje de los encuestados que compran Productos para el Hogar (Jul. 91), Menaje (Oct.93) en cada tipo de establecimiento.

\begin{tabular}{|c|c|c|c|c|c|c|c|}
\hline \multicolumn{8}{|c|}{ Productos para el Hogar } \\
\hline \multicolumn{9}{|c|}{ Enc. } & Tienda & Mercado & SP & GA & HP Otros \\
\hline $\begin{array}{c}\text { Total } \\
\text { Jul.91 }\end{array}$ & 1200 & 26 & 5 & 36 & 9 & 9 & 8 \\
\hline 65 y más & 196 & 34 & 4 & 31 & 5 & 5 & 2 \\
\hline Total Oct.93 & 1200 & 31 & 4 & 14 & 22 & 11 & 6 \\
\hline 65 y más & 196 & 40 & 4 & 14 & 16 & 4 & 3 \\
\hline Fuente: CIRES & $\mathbf{1 9 9 1} \boldsymbol{1} \mathbf{1 9 9 3}$ &
\end{tabular}

Fuente: CIRES, 1991 y 1993.

En lo referente a la compra de los productos para el hogar, eligen en mayor medida la tienda, mientras que el resto de la población realiza las compras de estos productos en el supermercado. Los grandes almacenes y los hipermercados son utilizados en un porcentaje menor por los mayores, por los motivos que hemos señalado con anterioridad. El menaje es comprado por la mayoría de la población en las tiendas especializadas, si bien es verdad que los mayores acuden en mayor número a ellas y, en menor porcentaje que el resto de la población, a los grandes almacenes y a los hipermercados, comportamiento que se repite en la compra de los anteriores productos.

\begin{tabular}{|c|c|c|c|c|c|c|c|}
\hline Porcentaje d & encuesta & $\begin{array}{r}\text { TABL } \\
\text { s que co } \\
\text { de estak }\end{array}$ & $\begin{array}{l}07 . \\
\text { an los Elec } \\
\text { niento. }\end{array}$ & lést & en $c$ & $a$ & tipo \\
\hline & & Electroc & ésticos & & & & \\
\hline & Enc. & Tienda & Mercado & SP & GA & HP & Dtros \\
\hline $\begin{array}{l}\text { Total } \\
\text { Jul.91 }\end{array}$ & 1200 & 33 & 1 & 4 & 26 & 9 & 11 \\
\hline 65 y más & 196 & 33 & 1 & 4 & 14 & 4 & 9 \\
\hline Total Oct.93 & 1200 & 37 & 1 & 3 & 25 & 9 & 9 \\
\hline 65 y más & 196 & 37 & 2 & 2 & 23 & 4 & 6 \\
\hline Fuente: CIRE & 991 y 1993 & & & & & & \\
\hline
\end{tabular}


Como se observa en la Tabla $N^{0}$ 7, la mayor parte del colectivo adquiere los electrodomésticos en las tiendas pequeñas, los grandes almacenes y los hipermercados son menos utilizados por las personas mayores para tal fin. Sin embargo, aún siendo los mismos tipos de establecimientos utilizados mayoritariamente por las personas mayores, se constata que la mayor parte de las personas mayores compran electrodomésticos en tiendas pequeñas, perdiendo el peso el resto de establecimientos, fundamentalmente debido a que las personas mayores comprarían menos electrodomésticos que el resto.

\begin{tabular}{|c|c|c|c|c|c|c|c|c|}
\hline \multicolumn{9}{|c|}{$\begin{array}{c}\text { TABLA No } 8 \text {. } \\
\text { Porcentaje de los encuestados que dice comprar las categorías de productos } \\
\text { indicada en los días señalados }\end{array}$} \\
\hline \multicolumn{9}{|c|}{ Alimento fresco } \\
\hline & Lunes & Martes & Miércoles & Jueves & Viernes & Sábado & Domingo & $\begin{array}{l}\text { No } \\
\text { fijo }\end{array}$ \\
\hline $\begin{array}{l}\text { Total } \\
\text { Oct.93 }\end{array}$ & 4 & 5 & 2 & 2 & 13 & 10 & $*$ & 43 \\
\hline 65 y más & 7 & 10 & 3 & 2 & 10 & 5 & * & 41 \\
\hline \multicolumn{9}{|c|}{ Ultramarinos } \\
\hline & Lunes & Martes & Miércoles & Jueves & Viernes & Sábado & Domingo & $\begin{array}{l}\text { No } \\
\text { fijo }\end{array}$ \\
\hline $\begin{array}{l}\text { Total } \\
\text { Oct.93 }\end{array}$ & 3 & 3 & 2 & 1 & 12 & 12 & $*$ & 60 \\
\hline 65 y más & 4 & 6 & 4 & 1 & 8 & 4 & $*$ & 64 \\
\hline \multicolumn{9}{|c|}{ Ropa y/o Calzado } \\
\hline & Lunes & Martes & Miércoles & Jueves & Viernes & Sábado & Domingo & $\begin{array}{l}\text { No } \\
\text { fijo }\end{array}$ \\
\hline $\begin{array}{c}\text { Total } \\
\text { Oct.93 }\end{array}$ & 1 & $*$ & 1 & 1 & 3 & 14 & $*$ & 80 \\
\hline 65 y más & 1 & $*$ & 2 & 1 & 1 & 5 & $*$ & 90 \\
\hline \multicolumn{9}{|c|}{ Menaje } \\
\hline & Lunes & Martes & Miércoles & Jueves & Viernes & Sábado & Domingo & $\begin{array}{l}\text { No } \\
\text { fijo }\end{array}$ \\
\hline $\begin{array}{c}\text { Total } \\
\text { Oct.93 }\end{array}$ & 1 & 1 & 1 & 1 & 3 & 12 & $*$ & 80 \\
\hline 65 y más & 1 & $*$ & 2 & 1 & 1 & 4 & $*$ & 92 \\
\hline \multicolumn{9}{|c|}{ Ultramarinos } \\
\hline & Lunes & Martes & Miércoles & Jueves & Viernes & Sábado & Domingo & $\begin{array}{l}\text { No } \\
\text { fijo }\end{array}$ \\
\hline $\begin{array}{c}\text { Total } \\
\text { Oct.93 }\end{array}$ & 1 & 1 & 1 & 1 & 2 & 11 & $*$ & 83 \\
\hline 65 y más & 1 & 1 & 1 & $*$ & 1 & 4 & $*$ & 92 \\
\hline
\end{tabular}




\section{Fuente: CIRES, 1993}

Con respecto al día de la semana en que efectúan sus compras, en un análisis de la Tabla $N^{0} 8$, observamos, que no existe un día fijo para adquirir los citados bienes. En todo caso entre los días donde se suelen hacer más compras son los viernes y los sábados, presentando los mayores porcentajes estos días que el resto de la población, mientras que el resto de días de la semana suelen hacer más compras sobre todo de alimento fresco y ultramarinos. Los mayores al tener más tiempo libre, se toman la compra como una actividad más lúdica, en la que emplean más tiempo que el resto de la población. Las personas mayores suelen preferir hacer la compra a diario y adquirir en cada acto pequeñas cantidades, sobre todo, en lo que se refiere a alimentos frescos, compran al día. Esto adquiere una cierta lógica si tenemos en cuenta que la actividad laboral deja poco tiempo para realizar las compras y el hecho de que la mujer trabaje cada vez en mayor número fuera del hogar, hace que se haga una compra semanal lo suficientemente grande para liberarse de estos quehaceres durante toda la semana.

\begin{tabular}{|c|c|c|c|c|c|c|c|c|c|}
\hline \multicolumn{10}{|c|}{$\begin{array}{l}\text { TABLA No } 9 . \\
\text { Porcentaje de los encuestados que compra cada categoría de productos en el } \\
\text { horario ofrecido }\end{array}$} \\
\hline \multirow{2}{*}{\multicolumn{2}{|c|}{$\begin{array}{r}\text { Total } \\
\text { Enc. }\end{array}$}} & \multicolumn{4}{|c|}{ Alimentos } & \multicolumn{4}{|c|}{\begin{tabular}{|l|} 
Otros productos \\
\end{tabular}} \\
\hline & & $\begin{array}{l}\text { Antes de } \\
\text { las } 15 \mathrm{~h} .\end{array}$ & $\begin{array}{c}\text { Después } \\
\text { de las } \\
15 \mathrm{~h} .\end{array}$ & Depende & NS/NC & $\begin{array}{c}\text { Antes } \\
\text { de } \\
\text { las } \\
15 \mathrm{~h} .\end{array}$ & $\begin{array}{c}\text { Después } \\
\text { de las } \\
15 \mathrm{~h} .\end{array}$ & Depende & NS/NC \\
\hline $\begin{array}{l}\text { Total } \\
\text { Jul.91 }\end{array}$ & 1200 & 53 & 14 & 22 & 11 & 19 & 41 & 3 & 6 \\
\hline 65 y más & 196 & 66 & 1 & 16 & 16 & 29 & 24 & 32 & 14 \\
\hline $\begin{array}{c}\text { Total } \\
\text { Oct.93 }\end{array}$ & 1200 & 53 & 13 & 24 & 10 & 23 & 33 & 40 & 5 \\
\hline 65 y más & 196 & 65 & 5 & 20 & 11 & 30 & 19 & 42 & 9 \\
\hline
\end{tabular}

Referido al asunto de los horarios de compra -asunto de interés, pues afecta a la organización del tiempo en la vida cotidiana-, al analizar la Tabla $\mathrm{N}^{0}$ 9, y en lo que respecta a los alimentos -que tal como vimos en la Tabla $\mathrm{N}^{\mathrm{o}} 1$, era un capítulo 
relevante en los hábitos de consumo del consumidor mayor-, la mayor parte de los encuestados los adquieren antes de las 15 horas, este porcentaje es superior en el caso de los consumidores de mayor edad. En 1.991 el 66\% los compraba antes de las 15 horas y sólo el 1\% después de las 15 horas. Los mayores prefieren comprar los alimentos por las mañanas y evitan las grandes aglomeraciones, el resto de la población tiene que ajustar el horario de compra con otra serie de actividades, sobre todo laborales, que son las que ocupan más tiempo. Referido a la compra de otros productos, la mayor parte de la población los adquiere después de las 15 horas, mientas que los consumidores mayores las realizan en mayor número antes de las 15 horas, por lo que prefieren el horario de mañana para realizar las compras.

\begin{tabular}{|c|c|c|c|c|c|c|c|c|c|c|}
\hline \multicolumn{11}{|c|}{$\begin{array}{l}\text { TABLA No } 10 . \\
\text { Grado de preocupación por diferentes aspectos según una escala } \\
1-5, \text { de menor a mayor preocupación }\end{array}$} \\
\hline Oct.90/Jul.91 & \begin{tabular}{|l|} 
Total \\
Enc.
\end{tabular} & \begin{tabular}{|l|} 
Trabajo \\
afectiva
\end{tabular} & $\begin{array}{l}\text { Vida } \\
\text { amigo }\end{array}$ & $\begin{array}{c}\text { Problema } \\
\text { físico }\end{array}$ & $\begin{array}{l}\text { Salud } \\
\text { familiar }\end{array}$ & $\begin{array}{l}\text { Aspecto } \\
\text { familiar }\end{array}$ & $\begin{array}{l}\text { Problema } \\
\text { preocup. }\end{array}$ & Dinero & Armonía & $\%$ \\
\hline Total & 12.000 & 3,3 & 3,3 & 2,7 & 3,6 & 2,7 & 3,7 & 3,4 & 3,5 & $49 \%$ \\
\hline 65 y más & 1.965 & 1,7 & 2,7 & 2,1 & 3,8 & 2,1 & 3,1 & 3,0 & 3,2 & $30 \%$ \\
\hline \multicolumn{11}{|c|}{ Fuente: CIRES, 1991 y 1993} \\
\hline
\end{tabular}

Por último, y referido al grado preocupación que sienten las personas mayores, la salud aparece referida en el primer lugar de preocupación. En segundo lugar en orden de preocupación están los problemas familiares, y en tercer lugar el dinero. Al resto de la población lo que primero le preocupa son los temas relacionados con la familia, la salud y en tercer lugar, también el dinero. Por lo tanto, lo económico ocupa un lugar importante en la vida de los mayores, al igual que ocurre con el resto de la población; el cómo llegar a fin de mes, el ahorro, la pensión, el consumo... son temas que, de hecho, preocupan a nuestros mayores. Porque "lo económico" ocupa un lugar primigenio en la vida cotidiana del sujeto mayor desde el mismo hontanar de la jubilación (y aún antes), pasando por sus conversaciones cotidianas, y sus propias circunstancias (salud, viudedad, situación familiar, etc) se están marcando unas actitudes muy mediatizadas por lo económico. 


\section{Bibliografía}

ALONSO L E, Conde F (1.994) La Historia de la Sociedad de consumo en España, Ed. Debate, Madrid.

ALFAGEME A (1.999) "La soledad y el género. Una aproximación factorial a la desigualdad económica de los ancianos mayores en los años 90", en Rev. Multidisciplinar de Gerontología, vol 9, nº 3. Nexus. Barcleona.

BAZO MT (1.998) "Aportaciones de las personas mayores a la sociedad". REIS N 73. CIS. Madrid.

BOURDIEU P (1.988) La distinción (criterios y bases sociales del gusto), Tecnos, Madrid.

CABRE A (1.993) "Algunas consideraciones sobre el envejecimiento demográfico en España y su evolución futura", en P. Sánchez Vera, Sociedad y Población Anciana. Universidad de Murcia, Murcia.

CASTILLO CASTILLO J (1.987) Sociedad de consumo a la española, Eudema, Madrid.

CONDE F (1.994) "Notas sobre la génesis de la sociedad de consumo en España", en Política y sociedad No 16 , Universidad Complutense de Madrid. Madrid.

CUMMING E, HENRY W (1.961) Growing Old.: The Process of Disengagement, New York, Bassic Book. 
DÍEZ NICOLÁS J (1.997) "La estructura de los hogares españoles", en R. Puyol, Dinámica de la Población Española, Síntesis, Madrid. .

GAVIRIA M (1.996) La séptima potencia, Ediciones B, Barcelona.

GONZÁLEZ A at olt (1.996) "Juego patológico: un modelo de estudio epidemiológico en población general", en Rev. Adicciones, vol 8, No 2, Sociodroga-alcohol, Palma de Mallorca.

GRANDE ESTEBAN I (1.993) Marketing estratégico para la Tercera Edad, ESIC. Madrid.

GRANDE ESTEBAN, I (1.999) "Las actitudes de los consumidores mayores ante la compra y sus consecuencias sobre la gestión de marketing", en Estudios sobre Consumo, núm. 51, Ministerio de Sanidad y Consumo, Madrid.

GUBRIUM, J. (1.973) The Myth of the Golden Year: A Socio-Environemental Theory og Aging. Springfield III, Charles C Thomas.

MANNHEIM, K. (1.993) "El problema de las generaciones", REIS 1993, pp.193-242, CIS, Madrid.

MORAGAS, R.(1.991) Gerontología Social (Envejecimiento y Calidad de Vida). Herder. Barcelona.

NAVARRO, M. (1.987) "Producción y Consumo", en Garmendia J.A., Navarro M, Parra Luna F. Sociología Industrial y de la empresa, Ed. Aguilar, Madrid. 
NAVARRO, M. (1.992) "Apuntes para una teoría de la cultura económica", en Moya C, Pérez-Agote A, Salcedo J, Tezanos J.F., Escritos de Teoría Sociológica. CIS. Madrid. ORTI A (1.968) Estudio Región Norte (citado por L.E. Alonso y F. Conde, 1.994, p. 205).

PANIAGUA A (1.993) "Consideraciones sobre el concepto de pobreza aplicado a los ancianos", en Revista Española de Geriatría y gerontología, No 28, 1, 12-17, Madrid.

PÉREZ ORTIZ L (1.998) Las necesidades de las personas mayores, INSERSO, Ministerio de Trabajo y Asuntos sociales. Madrid.

PÉREZ-AGOTE A (1.978) "Hacia un estatuto teórico del consumo: Jean Baudrillad o la abstracción lógica de la forma", en Jiménez Blanco J, Moya C. Teoría Sociológica Contemporánea. Tecnos. Madrid.

RUÍZ DE MAYA S (1.999) "Los grupos y el análisis de la familia" (cap. 7), en Rivas J.A. et al. Comportamiento del consumidor. ESIC. Madrid.

SÁNCHEZ VERA p (2.000) "Sociología de la Vejez versus Economía de la Vejez". Papers No 61.S:P: Univ. Autónoma de Barcelona. Barcelona.

SARA, N (1.993) "El filón de la Tercera Edad", en Actualidad Económica, No 1.815, Abril. 